\title{
Comparison of surface soil moisture from SMOS satellite and ground measurements
}

\author{
Bogusław Usowicz ${ }^{1}$, Wojciech Marczewski ${ }^{2}$,Jerzy B. Usowicz ${ }^{3}$, Mateusz I. Eukowski ${ }^{1}$, and Jerzy Lipiec ${ }^{1}$ \\ ${ }^{1}$ Institute of Agrophysics, Polish Academy of Sciences, Doświadczalna 4, 20-290 Lublin, Poland \\ ${ }^{2}$ Space Research Centre, Polish Academy of Sciences, Bartycka 18A, 00-716 Warsaw, Poland \\ ${ }^{3}$ Torun Centre of Astronomy of the Nicolaus Copernicus University, Gagarina 11, 87-100 Torun, Poland
}

Received December 12, 2013; accepted May 12, 2014

A b s t r a c t. Soil moisture datasets at various scales are needed for sustainable land use and water management. The aim of this study was to compare soil moisture ocean salinity satellite and in situ soil moisture data for the Podlasie and Polesie regions in Eastern Poland. Both regions have similar climatic and topographic conditions but are different in land use, vegetation, and soil cover. The test sites were located on agricultural fields on sandy soils and natural vegetation on marshy soils that prevail in the Podlasie and Polesie regions, respectively. The soil moisture ocean salinity soil moisture data were obtained from radiometric measurements $(1.4 \mathrm{GHz})$ and the ground soil moisture from sensors at a depth of $5 \mathrm{~cm}$ during the years 2010-2011. In general, temporal patterns of soil moisture from both satellite and ground measurements followed the rainfall trend. The regression coefficients, Bland-Altman analysis, concordance correlation coefficient, and total deviation index showed that the agreement between ground and soil moisture ocean salinity derived soil moisture data is better for the Podlasie than the Polesie region. The lower agreement in Polesie was attributed mostly to the presence of the widespread natural vegetation on the wetter marsh soil along with minor contribution of agriculturally used drier coarse-textured soils.

$\mathrm{K}$ e y w o r d s: surface soil moisture, SMOS and ground measurements, Bland-Altman analysis, concordance correlation coefficient, total deviation index

\section{INTRODUCTION}

Soil moisture (SM) significantly affects water and energy exchange at the land surface-atmosphere interface and thereby is one of the key variables in numerous disciplines such as hydrology, soil science, and climatology. It is the most important source of water for agricultural crops

*Corresponding author e-mail: m.lukowski@ipan.lublin.pl

**The work was financially supported in part by the ESA Programme for European Cooperating States (PECS), No. 98084 SWEX-R, Soil Water and Energy Exchange/Research, AO3275 (2009-2012) and No. 4000107897/13/NL/KML ELBARA_PD (Penetration Depth), AO 1-7021 (2013-2015). and natural vegetation. Therefore, SM datasets of good quality at various scales are needed for sustainable land, crop, and water management and land surface modelling (Al Bitar et al., 2012; Lipiec et al., 2013; Smith et al., 2012).

Several satellite missions have shown the potential of using space-borne microwave remote sensing radiometry for the evaluation of surface SM at a global scale. The main previous satellite missions in radiometry including the Scanning Multichannel Microwave Radiometer (launched in 1978) and the Advanced Microwave Scanning Radiometer (launched in 2002) were operated in the C-Band (frequency $\mathrm{f}=4-8 \mathrm{GHz}$, wavelength $\lambda=7.5-3.8 \mathrm{~cm}$ ) (Seneviratne et al., 2010). The recently launched (November, 2009) soil moisture ocean salinity (SMOS) satellite from the European Space Agency (ESA) operates in the passive L-band microwave ( $\mathrm{f}=1-2 \mathrm{GHz}, \lambda=30-15 \mathrm{~cm}$ ), which is a preferred frequency for soil moisture retrieval (Kerr et al., 2001, 2010; Wagner et al., 2006). This wavelength penetrates well through the atmosphere and clouds. The instrument probes the earth surface soil approximately to the top $5 \mathrm{~cm}$ (Kerr et al., 2012). The new SMOS two-dimensional Y-shaped microwave imaging radiometer with aperture synthesis (MIRAS) and advanced multi-angle (from 0 to $55^{\circ}$ ) fully polarimetric system offers first-time opportunities for retrieving global soil moisture data with an accuracy of $0.04 \mathrm{~m}^{3} \mathrm{~m}^{-3}$ or better and a spatial resolution of less than $45 \mathrm{~km}$ with a revisit time of approximately three days (Kerr et al., 2001, 2010). SMOS provides geo-located data in the discrete global grid (DGG) hexagonal cells (ISEA4H9 system (Pinori et al., 2008)). SMOS microwave L-band measurements are also related to water held in vegetation. Patton and Hornbuckle (2013) revealed that the change in SMOS data over the growing season could be related to crop yields.

(C) 2014 Institute of Agrophysics, Polish Academy of Sciences 
It is therefore essential at the present step of the mission to compare the SMOS SM products with in situ measurements. Results of such studies obtained so far in the soil moisture networks have confirmed that the SMOS-derived soil moisture products are a reliable and important source of data for monitoring water in soils (Lacava et al., 2012). At the same time, the analyses revealed that soil moisture was very variable in space and time due to heterogeneous topography, soil and land cover properties, vegetation types, and climatic drivers that complicate comparisons between satellite pixels and point (in situ) measurements. Bircher et al. (2012) reported that land cover strongly influenced the SMOS soil moisture algorithm through both the choice of the retrieval model and high non-linearity of vegetation parameters.

Most recent papers also discuss scale effects due to the large gap between spatial scales of SMOS and estimations derived from ground based data on soil moisture (Bircher et al., 2012; Dente et al., 2012). The authors pointed out limitations associated with the number and spatial extent of distributed ground measurements to represent accurately the satellite scale. This leads to the deviations between satellite and ground-based measurements. To diminish the deviations, the in situ efforts should focus on separation of the respective contribution of these factors under a broad range of environmental conditions (Bircher et al., 2012; Juglea et al., 2010) before the planned refinement of the retrieval algorithm and data reprocessing (Dente et al., 2012). This should allow one to obtain more consistent data and yield quantitative maps of global soil moisture dynamics that is one of the main objectives of the SMOS mission (Kerr et al., 2012). The current and future datasets collected in several countries including Poland and available in the International Soil Moisture Network (ISMN, 2012) can be an important resource for validating and improving satellite-derived soil moisture products (Marczewski et al., 2010).

The aims of the paper were:

- to compare the SMOS satellite SM with in situ soil moisture data collected in the Podlasie and Polesie regions (Eastern Poland) located under similar climatic and topographic conditions but having different land and soil cover;

- to test the suitability of the Bland-Altman plot, concordance correlation coefficient (CCC), and total deviation index (TDI) for comparison of ground and satellite measurements.

\section{MATERIALS AND METHODS}

The study was carried out in two adjacent regions Podlasie (N 51 59' 24", E $\left.22^{\circ} 33^{\prime} 37^{\prime \prime}\right)$ and Polesie (N $51^{\circ}$ 23' 43", E $23^{\circ} 11^{\prime}$ '54") in Eastern Poland. The climate in both regions is continental with high temperatures during summer and long and frosty winters.

The average annual air temperature in the Podlasie region is about $7.3^{\circ} \mathrm{C}$. During 50-year (1949-1998) observations, the warmest month was July $\left(17.7^{\circ} \mathrm{C}\right)$ and the coldest January $\left(-3.6^{\circ} \mathrm{C}\right)$. Distribution of precipitation throughout the year indicates the occurrence of the highest rainfall in June and July (over $70 \mathrm{~mm}$ ) and the lowest (less than $30 \mathrm{~mm}$ ) in January, February, and March. Rainfalls are substantially higher during summer $(212 \mathrm{~mm})$ than in winter (83 mm). Rainfall during the growing season (AprilSeptember), $350.9 \mathrm{~mm}$, accounted for $65.4 \%$ of the annual precipitation and ranged from 224 to $530 \mathrm{~mm}$ over the 50 years.

The long-term average annual temperature in Polesie was $7.3^{\circ} \mathrm{C}$. The coldest month was January $\left(-4.1^{\circ} \mathrm{C}\right)$ and the warmest July $\left(17.9^{\circ} \mathrm{C}\right)$. The average long-term annual total precipitation was $542 \mathrm{~mm}$ and, in extremely dry and wet years, it reached 424 and $778 \mathrm{~mm}$, respectively (Usowicz et al., 2009). The annual sum fluctuated in a wide range from 78 to $153 \%$ with respect to the long-term average. Summer halfyear precipitation of the hydrological year (May-October), which is decisive for growth and crop production, has a distinct advantage over the winter half-year (November to April). The summer and winter half-year rainfalls were $349 \mathrm{~mm}$ $(64.4 \%)$ and $193 \mathrm{~mm}(35.6 \%)$ of the annual sum. The autumn (September-November) sum of precipitation was higher than that for spring (March-May). The maximum monthly precipitation was recorded in July and June (70-85 $\mathrm{mm}$ ) and the minimum in January and February $(20-30 \mathrm{~mm})$. Yearly precipitations consist mostly of rainfalls with a proportion of solid precipitation below $17 \%$ and average duration of snow cover 70-75 days during the year.

The topography in both regions is mostly flat, with little variation in absolute altitudes (less than $20 \mathrm{~m}$ ). Soils derived from loose sands, loamy sands, and loams prevail in Podlasie, whereas in Polesie a large area is occupied by marshy soils along with peat-lands and sands. The prevailing land cover type in Podlasie is arable land with the most frequent crops: barley, grass, and winter wheat, and additionally maize and potatoes (intermixed with forest and shrub/grassland), whereas in the Western Polesie the prevailing natural vegetation forest and shrub/grassland is intermixed with arable land (Fig. 1 from CORINE, CLC6). Part of the Polesie region belongs to the Poleski National Park with wellpreserved exceptional richness of unique flora and fauna and harsh character built over millenniums. A characteristic feature of the Park is the worldwide rarest high peat bogs called Krowie Bagno (Cow Marsh). Specification of the land use is given in Table 1 and the map in Fig. 1, based on CORINE classes (CLC6).

For further analyses, two Areas of Interests (AOI) in Polesie and Podlasie were chosen (violet shapes in Fig. 1). These shapes are composed of 7 DGG SMOS 'pixels' to meet the area corresponding to the radiometric spatial resolution of SMOS. Ground measurements were performed in the smallest scales as indicated by the rectangles (RECT) in Fig. 1. Land use specification from CORINE (CLC6) indicates that Polesie, compared to the Podlasie region, is characterized by larger contribution of pastures and existence of inland marshes (Table 1). The data from CORINE may be useful for interpretation of differences between satellite 


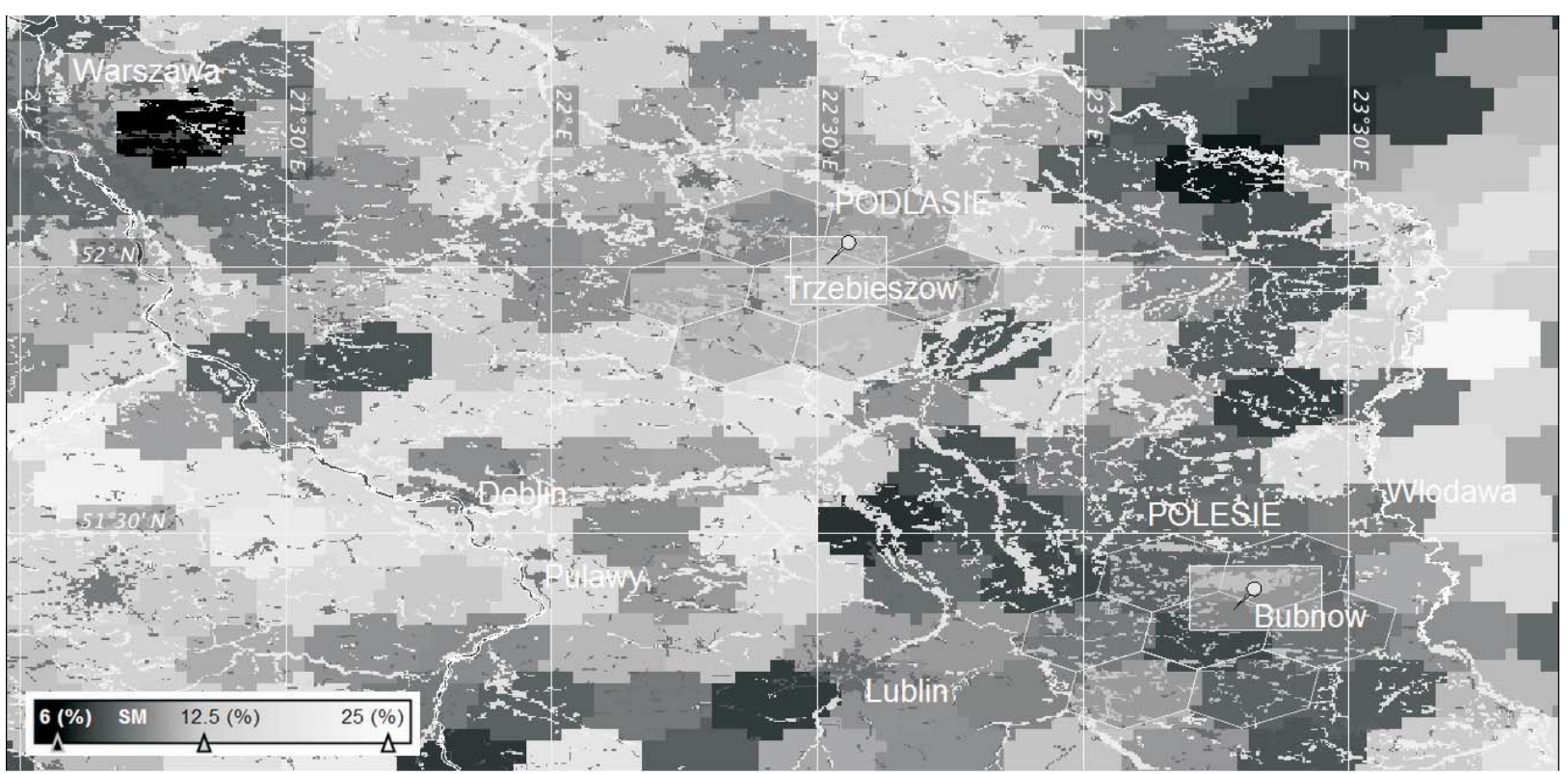

Fig. 1. Central-eastern region of Poland between the Bug and Vistula rivers. Two hexagonal shapes depict areas of interest (AOI) for Podlasie and Polesie in particular SMOS DGG pixels. Rectangular windows show selected areas of Polesie and Podlasie which were measured for soil physical properties. Area of each soil test field is comparable to the area of a single DGG SMOS pixel. The grey scale background presents SMOS L2 data values for SM, within the scale and histogram on the inset. The foreground overlay of CORINE CLC6 classes given by shapes is used for exemplification of forests and inhabited areas in broad regional scales.

T a bl e 1. Specification of the land use for the Podlasie and Polesie regions

\begin{tabular}{|c|c|c|c|c|c|}
\hline \multicolumn{6}{|c|}{ Land use (\%) } \\
\hline \multicolumn{2}{|l|}{ Regions } & \multicolumn{2}{|c|}{ Podlasie } & \multicolumn{2}{|c|}{ Polesie } \\
\hline Pixels & All & 7_DGG & 1_RECT & 7_DGG & 1_RECT \\
\hline No. of (MERIS) pixels considered & 484656 & 17929 & 2337 & 17667 & 3081 \\
\hline clc6_313_Mixed_forests & 7.25 & 6.78 & 2.95 & 11.00 & 7.85 \\
\hline clc6_311_Broad_leaved_forests & 5.63 & 3.58 & 5.61 & 5.66 & 6.69 \\
\hline clc6_312_Coniferous_forests & 14.69 & 11.42 & 7.74 & 5.42 & 3.38 \\
\hline clc6_222_Fruit_trees_plantations & 1.25 & 0.15 & 0 & 0.02 & 0 \\
\hline clc6_141_Green_urban & 0.09 & 0 & 0 & 0 & 0 \\
\hline _classes of clc6_HIGH_VEG & $\Sigma=28.91$ & $\Sigma=21.93$ & $\Sigma=16.30$ & $\Sigma=22.10$ & $\Sigma=17.92$ \\
\hline clc6_111_112_121_131_132_133 & 4.69 & 3.44 & 3.00 & 1.44 & 0.65 \\
\hline _Urban_industrial_inhabited & & & & & \\
\hline clc6_512_Water_bodies & 0.44 & 0.21 & 0 & 1.09 & 1.95 \\
\hline clc6_243_Agro_natural_veg & 0.40 & 0 & 0 & 0 & 0 \\
\hline clc6_231_Pastures & 12.86 & 16.36 & 21.01 & 17.50 & 26.10 \\
\hline clc6_411_Inland_marshes & 0.21 & 0 & 0 & 1.59 & 5.28 \\
\hline clc6_412_Peat_bogs & 0.04 & 0 & 0 & 0.75 & 0.10 \\
\hline _classes of clc6_LOW_VEG & $\Sigma=13.52$ & $\Sigma=16.36$ & $\Sigma=21.01$ & $\Sigma=19.84$ & $\Sigma=31.48$ \\
\hline _other LOW_VEG & 52.45 & 58.06 & 59.69 & 55.53 & 48.00 \\
\hline cross check $(\%)$ & $\Sigma=100$ & $\Sigma=100$ & $\Sigma=100$ & $\Sigma=100$ & $\Sigma=100$ \\
\hline
\end{tabular}


and ground soil moisture data. Table 1 shows the land use in fractions and demonstrates roughly how the heterogeneity of the target land contributes to real estimations depending on AOI location and the scale of AOI.

The automatic agro-meteorological stations (white pins in Fig. 1) are operated by the Institute of Agrophysics (Lublin, Poland) and located on most extensively occurring (representative) agricultural fields on sandy soil and the natural vegetation on the marsh soil for the Podlasie and Polesie regions, respectively (Marczewski et al., 2010). Those stations are localized in the central part of the chosen AOIs. The Polesie natural vegetation consists mostly of grass, shrubs, heather, and stunted forest trees. Soil moisture was measured in the years 2010 and 2011 using calibrated soil moisture ThetaProbe ML2x sensors connected to DL2e Data Logger (Delta-T Devices Ltd) at a depth of $5 \mathrm{~cm}$ every $10 \mathrm{~min}$. The sensors were calibrated with consideration of soil texture, bulk density, and temperature. During 2010/ 2011, winter temporal soil freezing disturbed the moisture measurements. For this reason, data from 2010 and 2011 are separated by a 'winter break' and examined separately. Rainfall data, collected at the stations, were also used. For each year, the mean and standard deviation were calculated. The minimum and maximum values with approximate dates of occurrence were specified.

Determination of the soil textural composition, reaction $(\mathrm{pH})$, and organic matter content at a depth $0-10 \mathrm{~cm}$ was performed at 464 and 86 sampling points within the Podlasie and Polesie regions, respectively rectangles in Fig. 1. The ground sampling points were located on most representative areas of the land use conditions.

SMOS observations were available from the beginning of 2010 (the satellite was launched in November 2009). Soil moisture is given by SMOS in the relative volumetric measure $\left(\mathrm{m}^{3} \mathrm{~m}^{-3}\right)$ with precision of about $0.04 \mathrm{~m}^{3} \mathrm{~m}^{-3}$. Soil moisture values are retrieved from the brightness temperature of natural electromagnetic emission in the spectral window (1.400-1.427 GHz). Data is collected in approximately 3.5-day cycles, which within the swath width of 1000 $\mathrm{km}$ observations enables one to estimate trends in temporal changes in 7 days. The SMOS orbit is Sun-synchronous: ascending passes repeatedly occur about the local sunrise time, and descending passes about the local sunset time. We used only ascending data because they were less noisy.

Spatial resolution of SMOS is estimated not less than $40 \mathrm{~km}$. This, more or less, corresponds to the area of 7 DGG pixels, as chosen before to be AOIs.

In order to relate SMOS retrieved soil moisture to the situ measurements, a linear regression model was suggested. Studies in areas of other scientific disciplines, for example in medicine, indicate that sometimes the simple regression analysis (the strength of the relation between two estimates as given by the coefficient of determination $\left(R^{2}\right)$ ) is not sufficient to draw correct conclusions about the effecti- veness of a new method. This is because correlation is best used when the reference method is low in error. However, both SM measurement techniques used in this study may have an inherent error.

Therefore, the Bland-Altman approach (Bland and Altman, 1986, 1999; Krouwer, 2008) was also adopted to plot the agreement between the in situ measured SM values with the SMOS data and to reveal the relationship between the differences and the magnitude of measurements.

The Bland-Altman plot (Bland and Altman, 1986, 1999), or a difference plot, is a graphical method to assess an agreement between two methods of measurement. This plot is widely used in medical statistics, biostatistics, and analytical chemistry. Researchers from other fields can easily recognise that it is identical to a Tukey mean-difference plot. In this graphical method, the differences (or alternatively the ratios) between the two methods are plotted against the averages of the two methods. Additionally, horizontal lines are drawn at the mean difference, and at the limits of agreement, which are defined as the mean difference plus and minus 1.96 times the standard deviation of the differences.

The Bland-Altman method assumes that two methods that measure the same physical quantity use the same scale of measurement. This implies that when plotted, the points should line up along the line $\mathrm{y}=\mathrm{x}$ (line of identity) (Deming, 1943). In our study, we will compare large-scale SMOS SM to small-scale ground SM data from local test sites. It is worth stressing that a high correlation does not automatically imply that there is good agreement between the two methods.

The SM differences between two methods were normally distributed and $95 \%$ of these differences were anticipated to lie between mean -1.96 SD and mean +1.96 SD, identified as 95\% limits of agreement (Bland and Altman, 1999; Borg et al., 2012; Krouwer, 2008).

The concordance correlation coefficient (Lin, 1989) evaluates the degree to which pairs of observations fall on the $45^{\circ}$ line through the origin. Lawrence Lin has developed the following formula for the concordance correlation coefficient:

$$
\rho_{c}=\frac{2 \rho \sigma_{x} \sigma_{y}}{\sigma_{x}^{2}+\sigma_{y}^{2}+\left(\mu_{x}-\mu_{y}\right)^{2}},
$$

where: $\rho$ is the Pearson correlation coefficient between the two variables, $\mu_{x}$ and $\mu_{y}$ are the means for the two variables and $\sigma_{x}^{2}$ and $\sigma_{y}^{2}$ are the corresponding variances.

The concordance correlation coefficient $\rho_{c}$ contains a measurement of precision $\rho$ and accuracy $C_{b}$ :

$$
\rho_{c}=\rho C_{b}
$$

$\rho$ measures how far each observation deviates from the best-fit line and is a measure of precision, and $C_{b}$ is a bias correction factor that measures how far the best-fit line deviates from the $45^{\circ}$ line through the origin and is a measure of accuracy. 
The total deviation index (TDI) describes a boundary such that a majority of the differences in paired measurements are within the boundary ie a probability interval. Lin (2000) derived the cumulative probability function of the square of the paired-measures difference variable, which is assumed to follow a non-central chi-squared distribution. Since the resulting equation turned out to be complicated, he derived further approximation with more desirable properties based on the asymptotic theory of the mean squared deviation (MSD).

\section{RESULTS AND DISCUSSION}

As can be seen in Table 2, the top layer of soils in Podlasie contains on average: $71.9,26.4,1.7 \%$ of sand, silt, and clay, respectively. The minimum contents of the respective fractions were 45,4 , and $0 \%$, respectively, and the maximum 95,54 , and $8 \%$. The reaction of the soils in the region was generally acidic or neutral, with average $\mathrm{pH} 4.3$ in $\mathrm{KCl}$ and 4.8 in $\mathrm{H}_{2} \mathrm{O}$. The minimum $\mathrm{pH}$ of the soils were 3.5 (in $\mathrm{KCl}$ ) and $3.9\left(\mathrm{H}_{2} \mathrm{O}\right)$, and the maximum 6.9 and 7.2 , respectively. The mean soil organic matter content was low; it amounted to $0.8 \%$ (layer $0-10 \mathrm{~cm}$ ) and ranged from 0.002 to $3.8 \%$.
The soils in the Polesie region have, on average, $82.9 \%$ of sand, $15.5 \%$ of silt, and $1.6 \%$ of clay. The minimum and maximum contents of these fractions were 58,3 , and $0 \%$ and 96,31 , and $15 \%$, respectively. The reaction of the soils was in general neutral, with mean $\mathrm{pH}$ of 6.2 in $\mathrm{KCl}$ and 6.6 in $\mathrm{H}_{2} \mathrm{O}$. The minimum $\mathrm{pH}$ values of the soils were 3.7 (in $\mathrm{KCl}$ ) and 4.7 (in $\mathrm{H}_{2} \mathrm{O}$ ), and maximum 7.7 and 7.8, respectively. The mean content of soil organic matter in Polesie was 3.2\% and it varied from 0.4 to $48.8 \%$.

The above data indicate that, on average, the soils of Polesie, compared to those of the Podlasie region, are slightly richer in sand and poorer in silt and substantially higher in organic matter (by almost 4 times).

As indicated by the coefficient of variation $(\mathrm{CV})$, the highest variability was recorded in the content of organic matter (187.2\%) and clay fraction (104.9\%) in Polesie. The corresponding CV values in Podlasie were significantly lower, namely 47.2 and $67.5 \%$. In both regions, the lowest variability was observed for the sand fractions (CV 9.1-12.9\%).

As can be seen from Table 3, there was more rainfall (by about $10 \%$ ) in Polesie than Podlasie in both years. In both regions, the precipitations were higher (by about 10\%) in

T a b l e 2. Statistics of soil texture, reaction $(\mathrm{pH})$, and organic matter content $(\mathrm{OM})$ at a depth of $0-10 \mathrm{~cm}$ for the Podlasie and Polesie regions

\begin{tabular}{|c|c|c|c|c|c|c|}
\hline \multirow{3}{*}{ Parameters } & \multicolumn{3}{|c|}{$\%$ content of fractions } & \multirow{3}{*}{$\mathrm{pH}_{\mathrm{KCl}}$} & \multirow{3}{*}{$\mathrm{pH}_{\mathrm{H}_{2} \mathrm{O}}$} & \multirow{3}{*}{$\begin{array}{l}\mathrm{OM} \\
(\%)\end{array}$} \\
\hline & $\begin{array}{l}\text { Sand } \\
1-0.05\end{array}$ & $\begin{array}{c}\text { Silt } \\
0.05-0.002\end{array}$ & $\begin{array}{c}\text { Clay } \\
<0.002\end{array}$ & & & \\
\hline & \multicolumn{3}{|c|}{$(\mathrm{mm})$} & & & \\
\hline \multicolumn{7}{|c|}{ Podlasie } \\
\hline Number of points & 464 & 464 & 464 & 464 & 464 & 464 \\
\hline Mean & 71.9 & 26.4 & 1.7 & 4.3 & 4.8 & 0.8 \\
\hline Standard deviation & 9.3 & 9.0 & 1.1 & 0.7 & 0.7 & 0.4 \\
\hline Coefficient of variation (CV) & 12.9 & 34.0 & 67.5 & 16.9 & 14.8 & 47.2 \\
\hline Skewness & 0.067 & -0.085 & 1.565 & 1.719 & 1.312 & 1.461 \\
\hline Kurtosis & -0.471 & -0.419 & 3.690 & 2.506 & 1.350 & 8.145 \\
\hline Minimum & 45.0 & 4.0 & 0.0 & 3.5 & 3.9 & 0.002 \\
\hline Maximum & 95.0 & 54.0 & 8.0 & 6.9 & 7.2 & 3.8 \\
\hline \multicolumn{7}{|c|}{ Polesie } \\
\hline Number of points & 86 & 86 & 86 & 87 & 87 & 87 \\
\hline Mean & 82.9 & 15.5 & 1.6 & 6.2 & 6.6 & 3.2 \\
\hline Standard deviation & 7.6 & 6.7 & 1.7 & 1.2 & 0.9 & 6.0 \\
\hline Coefficient of variation (CV) & 9.1 & 43.5 & 104.9 & 20.2 & 12.8 & 187.2 \\
\hline Skewness & -0.667 & 0.381 & 5.834 & -0.521 & -0.487 & 5.636 \\
\hline Kurtosis & 0.271 & -0.635 & 44.53 & -1.274 & -1.107 & 39.81 \\
\hline Minimum & 58.0 & 3.0 & 0.0 & 3.7 & 4.7 & 0.4 \\
\hline Maximum & 96.0 & 31.0 & 15.0 & 7.7 & 7.8 & 48.8 \\
\hline
\end{tabular}


T a b l e 3. Summary of basic statistics of precipitation and soil moisture content from satellite (ascending) and ground measurements in Podlasie and Polesie in 2010 and 2011

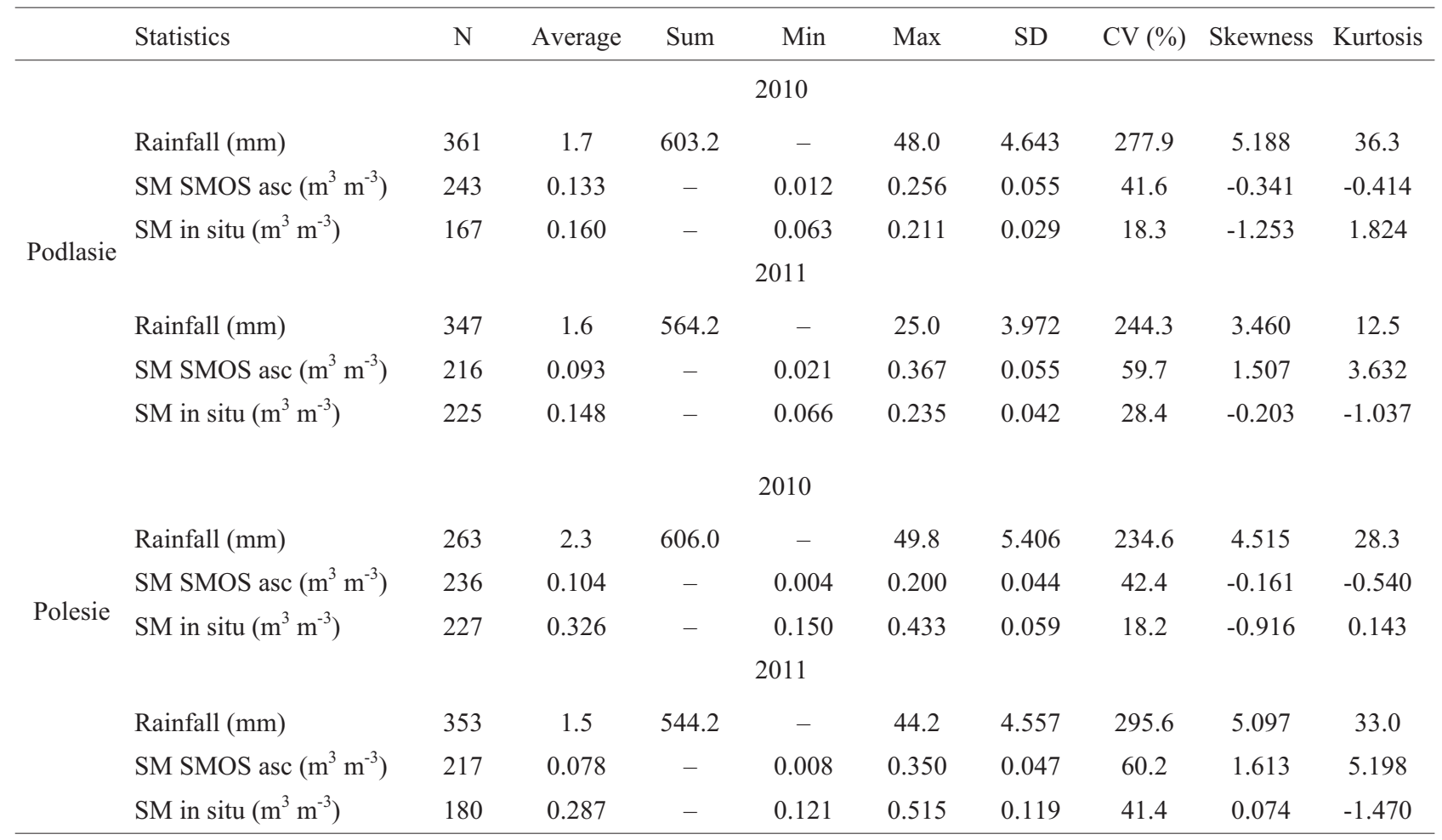

2010 than in 2011. Irrespective of the year, the mean SMOS SM (ascending pass) compared to in situ soil moisture was lower in both regions, to a higher extent for Polesie than Podlasie. The slightly higher soil moisture content from both SMOS-derived and ground soil moisture data in 2010 than in 2011 correspond well with greater precipitations in the former. The minimum and maximum and the coefficient of variation $\mathrm{CV}$ values for each set of soil moisture data and year were similar in both regions. In all cases, the $\mathrm{CV}$ was greater for the SMOS derived than ground measured data and in 2011 than in 2010.

Skewness and kurtosis values of the soil moisture distributions from satellite and ground-based measurements in a given year were similar in both regions (Table 3 ). Low left-hand and clear right-hand skewness of the satellite data were observed in 2010 and 2011, respectively. In 2010, the ground-based measurement compared to the satellite data were more left-hand skewed. The skewness of the ground measured SM declined in 2011 compared to 2010, but without a clear trend to the right-hand distribution, in contrast to the satellite data. The above differences in skewness and kurtosis can result from the measurement accuracy at a given soil moisture level. The difference may also be caused by the fact that SMOS measures only the top layer of soil, which is usually drier than the slightly deeper layers measured by in situ probes.
The temporal variability of soil moisture from both satellite and ground measurements follows the rainfall trend in both regions (Fig. 2). The most pronounced peaks of the SM at the 70th-100th day of the year are likely associated with spring freeze-thaw, whereas those at $>$ the 300th day of the year in 2010 correspond to autumn when SM usually increases as a result of low evapotranspiration.

In the biggest part of the study period, the SMOS derived, compared to in situ soil moisture contents, was lower. The considerably greater regression coefficients of the regression equations (Fig. 3) in Podlasie ie 0.625 in 2010 and 0.800 in 2011, than those of 0.310 and 0.281 , respectively, in Polesie can be indicative of better agreement between satellite and ground data in the Podlasie region. In addition, in situ soil moisture in Polesie compared to the Podlasie region shows larger amplitude (Fig. 2).

As can be seen from Fig. 3, the direction of the linear regression equations between the SMOS derived and in situ soil moisture contents is the same in both years. The direction can be indicative of the nature of a given place (point) and relationships that occur between that point and the larger area including the forms of the landscape. The determination coefficients of the equations, although not too high (from 0.111 to 0.460 ), appear satisfactory given that the ground-point and large area-satellite measurements are 
Podlasie
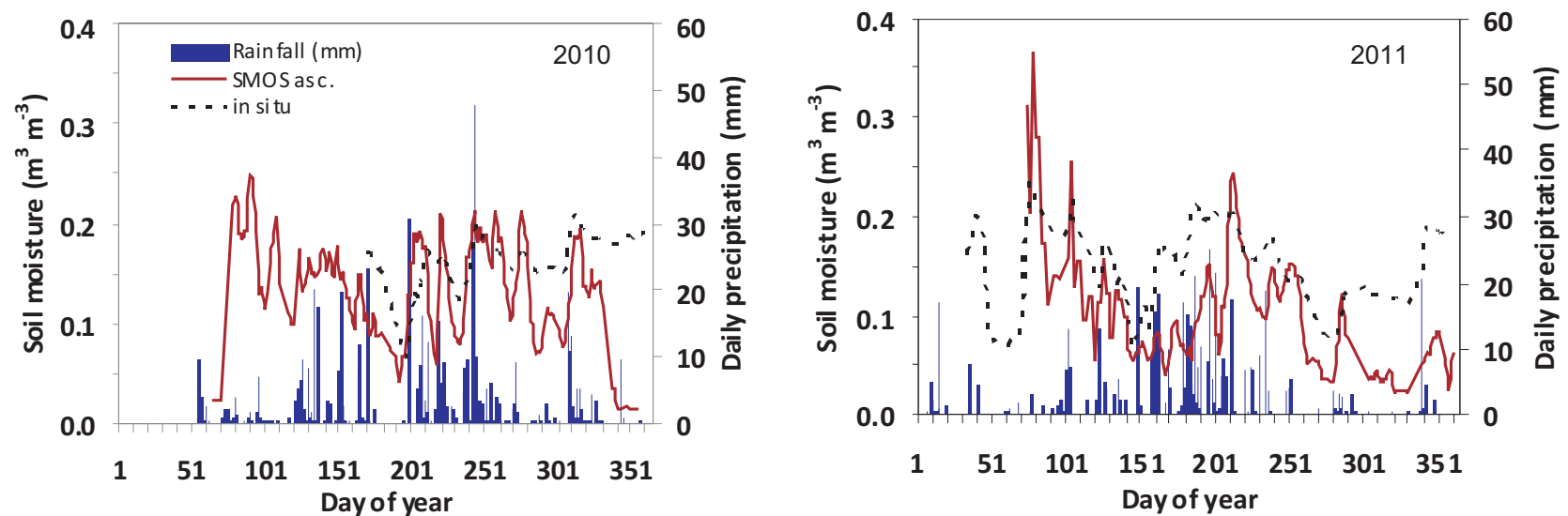

Polesie
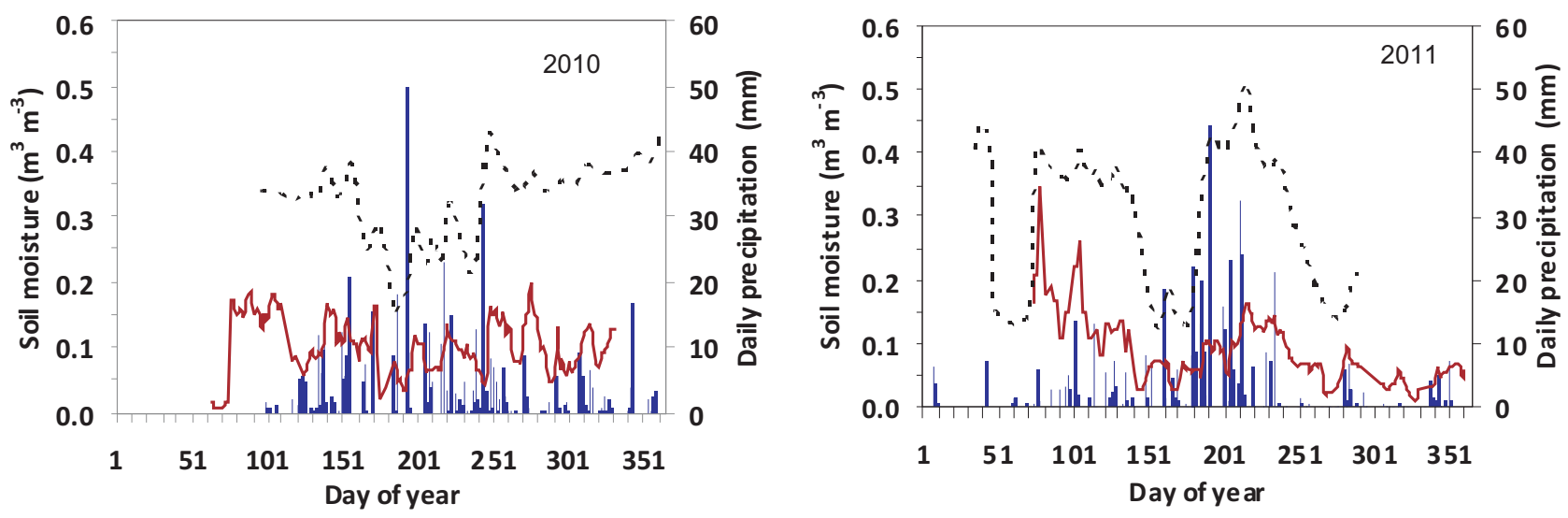

Fig. 2. Temporal SM SMOS and SM in-situ SM values with the daily precipitation data measured on the test sites.

compared. Irrespective of the region, the determination coefficients were appreciably greater in the less rainy year 2011 than in 2010.

The Bland-Altman plots (Fig. 4) show that a good agreement was found for Podlasie where SMOS data were only slightly underestimated, on average (bias) in the order of $0.034-0.055 \mathrm{~m}^{3} \mathrm{~m}^{-3}$ in both years. However, the underestimation by SMOS was appreciably greater for the Polesie region $\left(0.202-0.217 \mathrm{~m}^{3} \mathrm{~m}^{-3}\right)$. These results from both regions are consistent with findings from a range of validation locations under different site conditions (Al Bitar et al., 2012; Bircher et al., 2012; Dall'Amico et al., 2012; Gherboudj et al., 2012). From the Bland-Altman plots, it is also possible to observe that at lower soil moisture contents (left side in reference to the intersection point of the regression line with mean difference line) differences are in general greater and lower than the bias value for Podlasie and Polesie, respectively. However, at higher soil moisture contents (right side in reference to the intersection point of the regression line with mean difference line), the reverse was true. The range of the $95 \%$ limits of agreement $( \pm 1.96$ SD lines) in 2010 was approximately $0.2 \mathrm{~m}^{3} \mathrm{~m}^{-3}$ in both regions, whereas in the drier 2011 it slightly decreased (to about $0.18 \mathrm{~m}^{3} \mathrm{~m}^{-3}$ ) and appreciably increased (up to about $0.3 \mathrm{~m}^{3} \mathrm{~m}^{-3}$ ) for Podlasie and Polesie regions, respectively. The Bland-Altman plots show that a majority of the points are within the limits of agreement both in the Podlasie and Polesie regions.

Larger values of the concordance correlation coefficient (CCC) and those lower of the total deviation index (TDI) in Podlasie than Polesie (Table 4) indicate that agreement between ground measured and SMOS derived soil moisture data is better in the former. The agreement can be classified as 'moderate' for Podlasie and 'fair' for Polesie.

Overall, analysis of the results performed using regression coefficients, Bland-Altman plots as well as the CCC dispersions and TDI clearly indicates that the agreement between ground and SMOS derived soil moisture is better for Podlasie than the Polesie region. It is worth noting that the values of the assessment parameters are reproducible in 
Podlasie
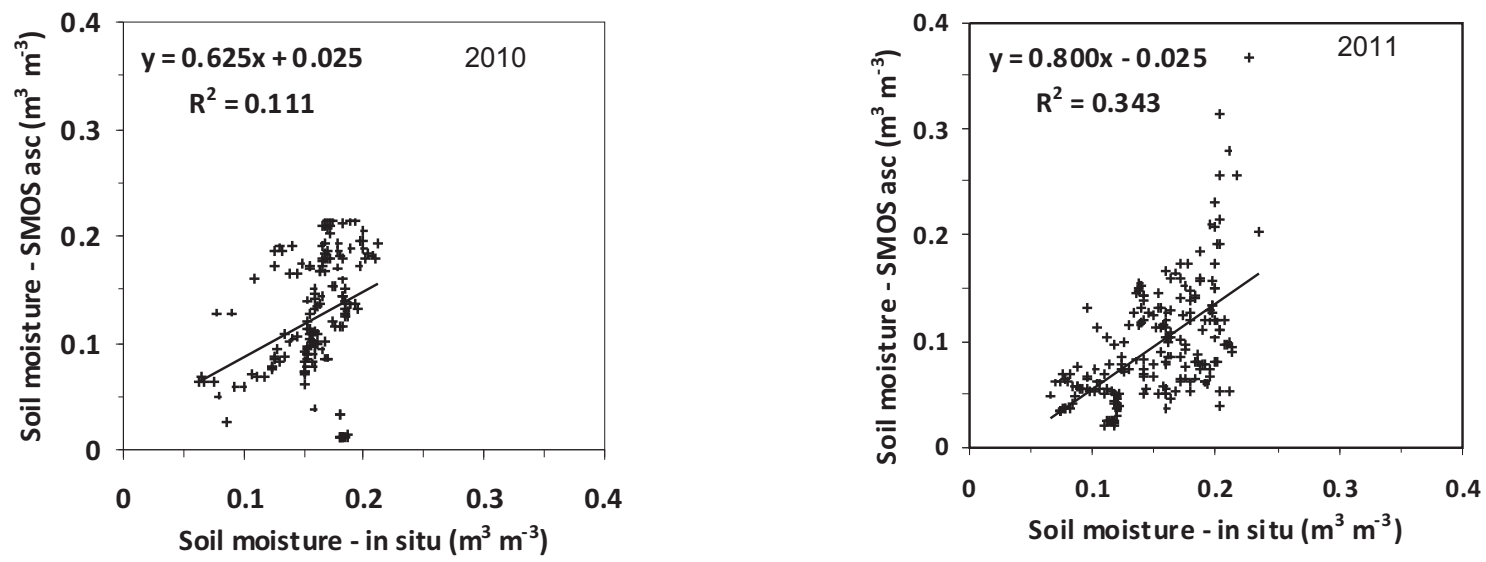

Polesie
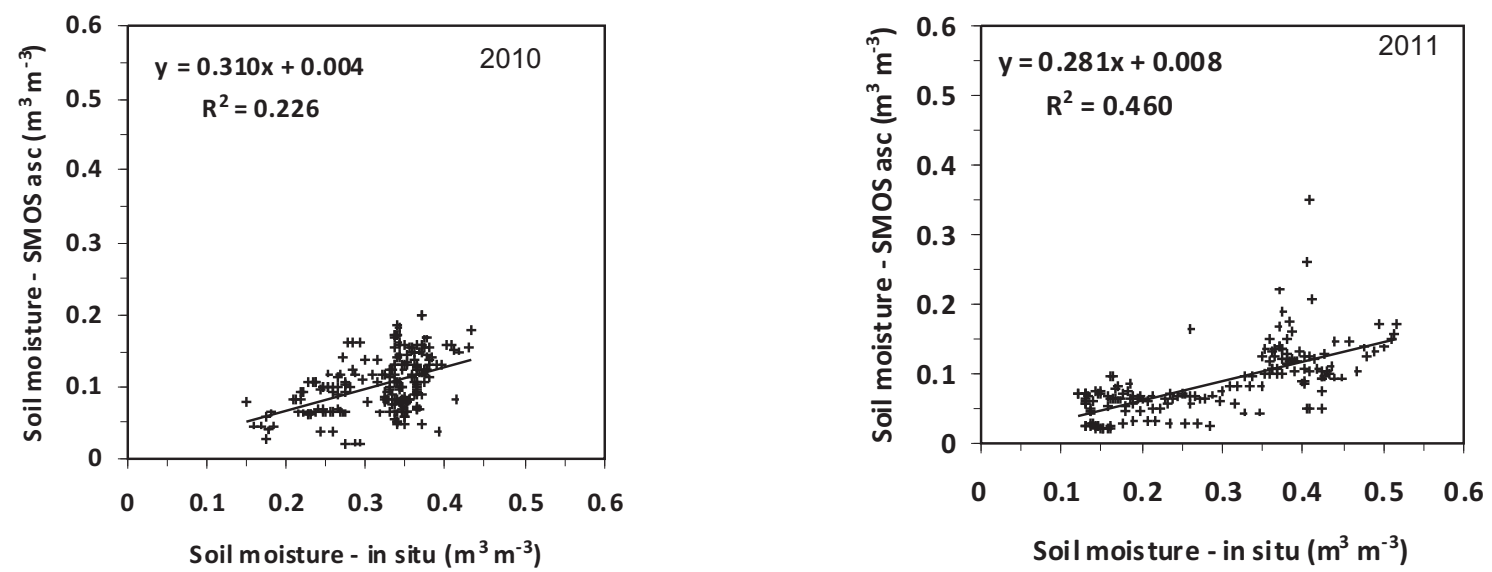

Fig. 3. Linear regression of SM measured by SMOS and SM measured on the ground. Both SM values are considered in 7-day averages (over the rectangular 7-day window) in 7-day steps.

both years for each region. The greater discrepancy in the SM between the in situ and SMOS data in the Polesie than Podlasie region can be due to diverse land use structure in spite of the soil moisture measurement station being located in the most representative natural vegetation on the marsh soil. The natural vegetation in the Polesie region was accompanied by a minor proportion of agriculturally used coarse-textured mineral soils. As shown by supplementary (ancillary) ground measurement campaigns in 2010-2011 (50-100 measurement points in each region), the SM in the points representing the typical natural vegetation varied from 0.20 to $0.65 \mathrm{~m}^{3} \mathrm{~m}^{-3}$ depending on the measurement time, whereas on the coarse-textured points it ranged barely from 0.02 to $0.3 \mathrm{~m}^{3} \mathrm{~m}^{-3}$. Consequently, the mean SMOS soil moisture, as integrated for the whole pixel, was substantially lower than the ground measured SM. These results reveal a significant effect of the patchy land use, resulting in large gradients of SM, on the validation results of the satellite data in the Polesie region. In the case of the Podlasie region, however, with more uniform land use structure and soil cover, the SM varied from 0.03 to $0.35 \mathrm{~m}^{3} \mathrm{~m}^{-3}$ and the differences between ground measured and SMOS derived soil moisture contents were much smaller. Also greater differences in ground compared to SMOS derived soil moisture contents between the regions investigated may have been influenced by heterogeneous soil and land cover in the Polesie region rather than climate, which was not much different.

The CCC or Interclass Correlation Coefficient can be interpreted as follows: 0-0.2 indicates poor agreement, 0.3-0.4 indicates fair agreement, 0.5-0.6 indicates moderate agreement, 0.7-0.8 indicates strong agreement, and 0.8 indicates almost perfect agreement. 

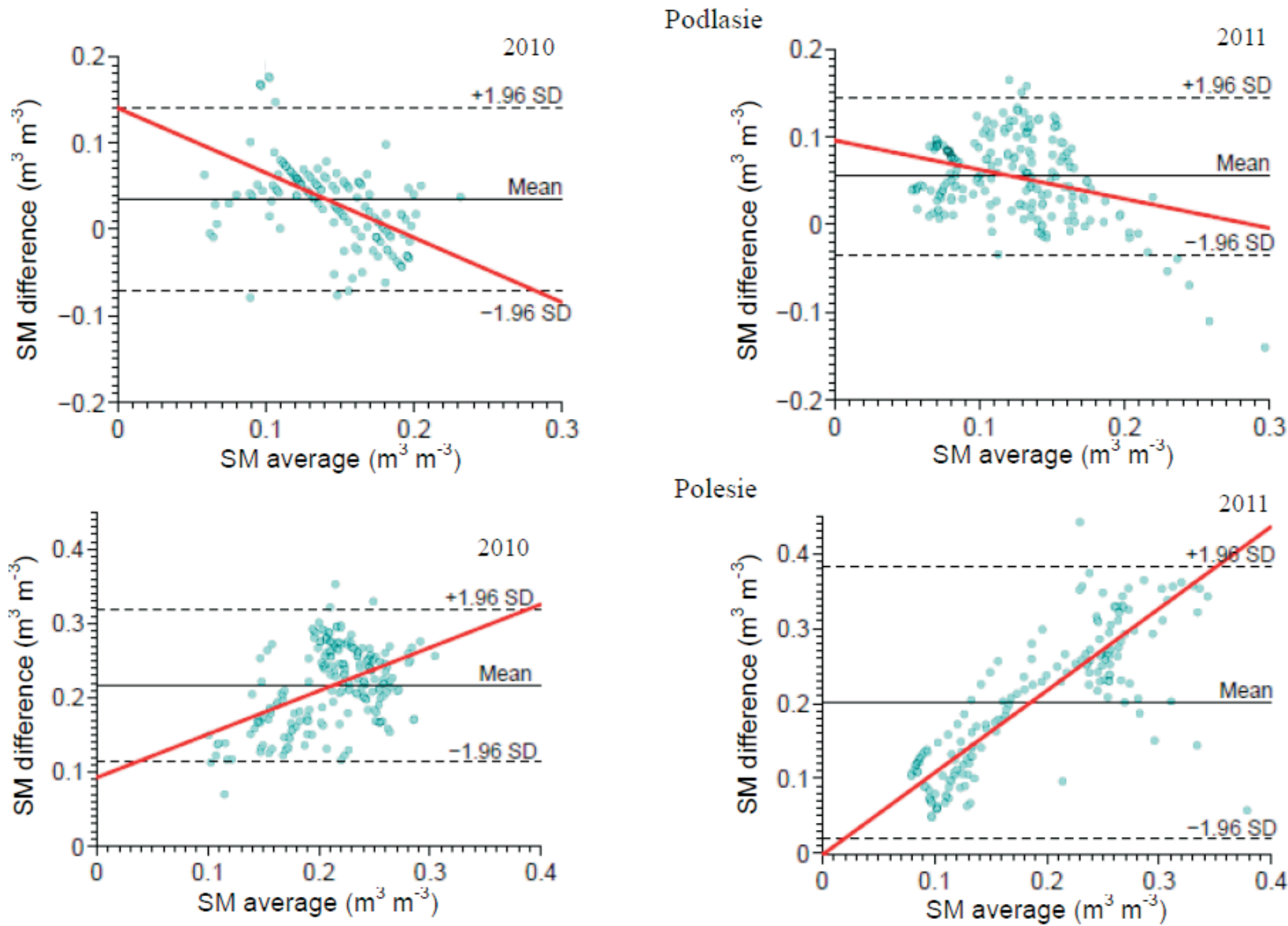

Polesie

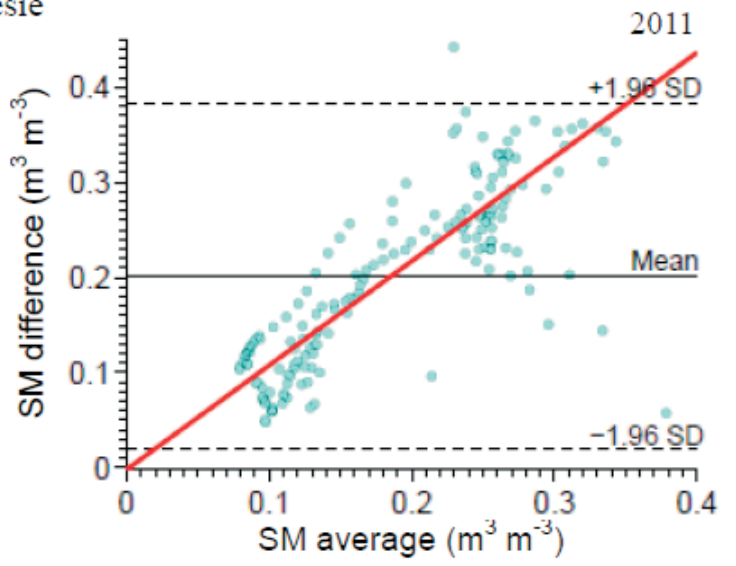

Fig. 4. Bland-Altman plots comparing SM in-situ ground based values to SM based on SMOS, derived for Podlasie and Polesie. Outer lines indicate a 95\% level of agreement. The central line shows average values of differences. 'SM difference' means the difference between in-situ and SMOS data, in ascending orbits (SM in-situ - SM SMOS asc.) 'SM average' means respectively (SM in-situ + SM $\mathrm{SMOS}$ asc)/2).

T a b I e 4. Concordance correlation coefficient (CCC) and total deviation index (TDI) results

\begin{tabular}{|c|c|c|c|}
\hline \multicolumn{2}{|c|}{ Podlasie } & \multicolumn{2}{|c|}{ Polesie } \\
\hline 2010 & 2011 & 2010 & 2011 \\
\hline$\rho_{c}=0.305$ & $\rho_{c}=0.558$ & $\rho_{c}=0.435$ & $\rho_{c}=0.464$ \\
\hline \multicolumn{4}{|c|}{ Total deviation index } \\
\hline 0.11 & 0.12 & 0.37 & 0.37 \\
\hline
\end{tabular}

\section{CONCLUSIONS}

1. Two areas under study were chosen for their representativeness of two larger regions constituted under similar climatic and topographic conditions in Eastern Poland, within different land uses and soil cover. Soil moisture ocean salinity data on soil moisture were compared to the ground based in situ data over the years 2010 and 2011. The in situ measurements were performed on most extensively occurring (representative) agricultural fields on sandy soil and the natural vegetation on marsh soil for the Podlasie and Polesie regions, respectively. Soil moisture ocean salinity data reproduced ground based soil moisture spatial patterns on scales of a region corresponding to more than several $(\mathrm{eg} 7)$ DGG pixels.

2. It was shown that the temporal patterns of soil moisture from both satellite and ground measurements followed the rainfall trend in both regions. Soil moisture ocean salinity estimations of soil moisture appeared to be underestimated with respect to ground based soil moisture data. 
3. The Bland-Altman plots revealed that the average difference (bias) between ground and soil moisture ocean salinity derived soil moisture and the $95 \%$ limits of agreement $( \pm 1.96$ SD) lines were lower for Podlasie than the Polesie region. In both Podlasie and the Polesie region, a majority of the points were within the limits of agreement.

4. Analysis of the results based on regression coefficients, the concordance correlation coefficient and the total deviation index showed that the agreement between ground and soil moisture ocean salinity derived soil moisture was better for Podlasie (classified as moderate) than Polesie (classified as fair) both in 2010 and 2011. This could be ascribed to the fact that the dominant natural vegetation with relatively wet soils in the Polesie region was accompanied by agriculturally used dry areas on coarse-textured soils. However, in the case of Podlasie, both land and soil covers were much more uniform.

5. The results of this study address the strong influence of the different land and soil cover under similar climate conditions as a potential error source in validation of soil moisture ocean salinity soil moisture results. The results of this study were needed for creating quantitative proofs on the relevance of soil moisture ocean salinity data to soil moisture in Poland. The study excludes the expectation that higher versions of the processing algorithm in soil moisture ocean salinity provides full agreement with the ground data, because soil moisture ocean salinity is aimed at creating areal measures of soil moisture and studying long term and long distance trends, which is not always available directly on the ground.

6. There is a well justified expectation that soil moisture ocean salinity data may provide a good database for estimating the sub-surface soil water content in absolute measures $\left(\mathrm{Mg} \mathrm{or} \mathrm{m}^{3}\right.$ of water), within a temporal averaging window of 7 days, and spatial integration in discrete global grid pixels covering the scale of the entire country or a larger region. Such data should be very useful in agrophysics, hydrology, and environmental research. Current activities will focus on the effect of the representativeness of the measurement sites using ground data from a recently established soil moisture and temperature network in Eastern Poland.

\section{REFERENCES}

Al Bitar A., Leroux D., Kerr Y.H., Merlin O., Richaume P., Sahoo A., and Wood E.F., 2012. Evaluation of SMOS Soil moisture products over continental U.S. using the SCAN/ SNOTEL network. IEEE T. Geosci. Remote, 50, 1572-1586.

Bircher S., Balling J.E., Skou N., and Kerr Y., 2012. Validation of SMOS brightness temperatures during the HOBE Airborne Campaign, Western Denmark. IEEE T. Geosci. Remote, 50, 1468-1482.
Bland J.M. and Altman D.G., 1986. Statistical method for assessing agreement between two methods of clinical measurement. The Lancet, 327(8476), 307-310.

Bland J.M. and Altman D.G., 1999. Measuring agreement in method comparison studies. Statistical Methods in Medical Res., 8, 135-160.

Borg I., Groenen P.J.F., and Mair P., 2012. Applied Multidimensional Scaling - Springerbriefs in Statistics. Springer-Verlag Berlin-Heidelberg, Germany.

Dall'Amico J.T., Schlenz F., Loew A., and Mauser W., 2012. First results of SMOS soil moisture validation in the upper Danube catchment. IEEE T. Geosci. Remote, 50, 1507-1516.

Deming W.E., 1943. Statistical adjustment of data. Wiley Press, NY, USA.

Dente L., Su Z., and Wen J., 2012. Validation of SMOS soil moisture products over the Maqu and Twente regions. Sensors, 12, 9965-9986.

Gherboudj I., Magagi R., Goita K., Berg A.A., Toth B., and Walker A., 2012. Validation of SMOS data over agricultural and boreal forest areas in Canada. IEEE T. Geosci. Remote, 50, 1623-1635.

International Soil Moisture Network, 2012. http://ismn.geo. tuwien.ac.at/networks/swex-poland/

Juglea S., Kerr Y., Mialon A., Lopez-Baeza E., Braithwaite D., and Hsu K., 2010. Soil moisture modelling of a SMOS pixel: interest of using the PERSIANN database over the Valencia Anchor Station. Hydrol. Earth Syst. Sci., 14, 1509-1525.

Kerr Y.H., Waldteufel P., Richaume P., Wigneron J.P., Ferrazzoli P., Mahmoodi A., Al Bitar A., Cabot F., Gruhier C., Juglea S.E., Leroux D., Mialon A., and Delwart S., 2012. The SMOS soil moisture retrieval algorithm. IEEE Trans. Geosci. Remote Sens., 50, 5, 1384-1403.

Kerr Y.H., Waldteufel P., Wigneron J., Delwart S., Cabot F., Boutin J., Escorihuela M.J., Font J., Reul N., and Gruhier C., 2010. The SMOS Mission: New Tool for Monitoring Key Elements of the Global Water Cycle. Proc. IEEE, 98, 666-687.

Kerr Y.H., Waldteufel P., Wigneron J., Martinuzzi J.M., Font J., and Berger M., 2001. Soil moisture retrieval from space: The Soil Moisture and Ocean Salinity (SMOS) mission. IEEE T. Geosci. Remote, 39, 1729-1735.

Krouwer J.S., 2008. Why Bland-Altman plots should use X, not $(\mathrm{Y}+\mathrm{X}) / 2$ when $\mathrm{X}$ is a reference method. Statistics in Medicine, 27, 778-780.

Lacava T., Matgen P., Brocca L., Bittelli M., Pergola N., Moramarco T., and Tramutoli V., 2012. A first assessment of the SMOS soil moisture product with in situ and modelled data in Italy and Luxembourg. IEEE Trans. Geosci. Remote Sens., 50, 5, 1612-1622.

Lin L.I-K., 1989. A concordance correlation coefficient to evaluate reproducibility. Biometrics, 45, 255-268.

Lin L.I-K., 2000. Total deviation index for measuring individual agreement with applications in laboratory performance and bioequivalence. Statistics in Medicine, 19, 255-270. 
Lipiec J., Doussan C., Nosalewicz A., and Kondracka K., 2013. Effect of drought and heat stresses on plant growth and yield: a review. Int. Agrophys., 27, 463-477.

Marczewski W., Slominski J., Slominska E., Usowicz B., Usowicz J., Romanov S., Maryskevych O., Nastula J., and Zawadzki J., 2010. Strategies for validating and directions for employing SMOS data, in the Cal-Val project SWEX (3275) for wetlands. Hydrol. Earth Syst. Sci. Discuss., 7, 7007-7057.

Patton J.C. and Hornbuckle B.K., 2013. Initial validation of SMOS vegetation optical thickness in Iowa. IEEE Geosci. Remote Sensing Lett., 10(4), 647-651.

Pinori S., Crapolicchio R., and Mecklenburg S., 2008. Preparing the ESA-SMOS (Soil Moisture and Ocean Salinity) mission - Overview of the User Data Products and Data Distribution Strategy. Microwave Radiometry and Remote Sensing of the Environment, doi:10.1109/ MICRAD.2008.4579480.
Seneviratne S.I., Corti T., Davin E.L., Hirschi M., Jaeger E.B., Lehner I., Orlowsky B., and Teuling A.J., 2010. Investigating soil moisture-climate interactions in a changing climate - a review. Earth-Sci. Reviews, 99(3-4), 125-161.

Smith A.B., Walker J.P., Western A.W., Young R.I., Ellett K.M., Pipunic R.C., Grayson R.B., Siriwidena L., Chiew F.H.S., and Richter H., 2012. The Murrumbidgee soil moisture monitoring network data set. Water Res. Res., 48, W07701, doi:10.1029/2012WR011976.

Usowicz B., Marczewski W., Lipiec J., Usowicz J.B., Sokołowska Z., Dąbkowska-Naskręt H., Hajnos M., and Lukowski M.I., 2009. Water in the soil - ground and satellite measurements in studies on climate change (in Polish). Foundation for the Development of Agrophysical Sciences, Committee for Agrophysics PAS, Monograph, Lublin, Poland.

Wagner W., Naeimi V., Scipal K., de Jeu R., and MartinezFernandez J., 2007. Soil moisture from operational meteorological satellites. Hydrogeology J., 15(1), 121-131. 